\section{Beth Posner}

Beth Posner is head of library resource sharing, the Graduate Center, City University of New York.

Correspondence concerning this column should be addressed to Mark Shores; email: shoresml@miamioh.edu.
Whether you want to update your library's shelves of yoga books or support academic research in Eastern spirituality and Hinduism, this issue's column on yoga resources should be of great benefit. The author has compiled an excellent list of sources for both the practitioner of this ancient art and those curious about the philosophy behind it.-Editor

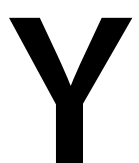

oga is a living practice of popular appeal, as well as an age-old tradition of scholarly interest. It is about the mind and the body, as well as the meaning of life and the nature of the universe. First introduced by Vedic priests to northern India five thousand years ago, the earliest yoga texts are two thousand years old. Its modern resurgence can be traced from the mid-nineteenth century, when it was popularized by Indian yogis and Western transcendentalists fascinated by Eastern philosophy and religion. As for contemporary yoga, it borrows from earlier traditions and texts as it also continues to evolve into new styles and systems. In this way, yoga is likely to remain relevant and vital, now and into the future.

The continuing and growing popularity of yoga of all sorts around the world speaks to the universal impulse people have to be well. For many, the initial draw is undoubtedly the fitness benefits of yoga postures (asana) - in terms of flexibility, balance, strength, and even cardio (if you do them fast enough), as well as its contributions to stress reduction. There are also students and scholars in universities studying yoga from a scientific or medical viewpoint, as well as through a theological, philosophical, psychological, or literary lens. Moreover, there are plenty of people who, after taking a yoga class or two, will want to learn more about a practice from which they experience meaningful benefits.

It is not surprising, therefore, to find library-card-carrying yogis turning to their local library collections for more information about everything from the value and values of yoga to its practice and purpose. Librarians, in response, should be collecting and sharing yoga resources in answer to questions, such as: What are the differences between styles of yoga? What are the risks and rewards of yoga practice? What is the history of yoga? Do the spiritual aspects of yoga make it a religion? Is yoga dualistic or monistic? Why is the Bhagavad Gita, about a warrior, a classic yoga text? What is the connection of karma and reincarnation and enlightenment? Why do many yoga classes begin with chanting Om (pronounced as Aum)?

It is because of yoga's long history and intricate and allencompassing philosophy that there are so many iterations and interpretations of the practice today. Traditional yoga still focuses on spirituality, using postures only as a way to 
center the mind and body for meditation and, ultimately, enlightenment. Yogic paths include raja yoga (focusing on meditation, which includes asanas), karma (action), bhakti (love or devotion), jnana (study), and tantra (ritual). Patanjali, a second-century Indian scholar and grammarian, writes about an eightfold path to living a good life, which includes asana practice, as well as ten ethical precepts: the yamas, which are requirements to be pure, content, disciplined, studious, and devoted, and the niymas, which are prohibitions against harm, deceit, theft, lust, and greed. Many types of yoga have also developed, such as Kundalini, Tantra, and Tibetan yoga. And, many teachers have gone on to develop their own schools, presenting yoga in their own ways, such as: Ananda, Anusara, Ashtanga, Bikram/Hot Yoga, Forrest, Integral, Iyengar, Jivamukti, Kripalu, Purna, Sivananda, Viniyoga, Vinyasa Flow, and Yin Yoga. Most share certain practices and beliefs, but because of their varying intensities and focuses, may not suit everyone. Each type of yoga also has its own texts, teachers, and traditions. Beyond these styles, there are classes in acro (acrobatic), partner, chair, hiking, restorative, tree, goat, laughter, and dog yoga (doga). And although traditional yogis do not agree that everything called yoga is yoga, there is also wine and chocolate, ganja, naked, beer, and rage yoga, depending on your mood or proclivities.

For many, the practice of yoga begins by learning some basic hatha yoga postures and coordinating movement with breath. One thousand years ago, the Hatha Yoga Pradipika identified thirty-two key postures and now there are thousands of variations. The practice of these postures is both relaxing and energizing, offering practitioners more awareness, calmness, and exercise. Moments spent on the yoga mat focus the attention and slow time; as opposed to using electronic devices that increase anxiety and decrease attention spans. This is why most yoga classes include asana, breathing (pranayama), and meditation, with the shared goal of building the focus, strength, balance, and flexibility needed for physical, mental, spiritual, and emotional health. It is also important to note that yoga is not only for the flexible; postures can be adapted for specific physical needs and therapeutic adjustments can even aid in healing.

As for the spiritual dimensions and mystical claims of yoga, there is also much to learn; perhaps the answers to all questions do lie in yoga study? Still, although yoga is an ancient practice offering valuable ideas and insights, it can also be confusing and elicit suspicion from many casual practitioners who do not believe in enlightenment and may be put off by the perception that yoga is "new agey." For many, there is more value in exploring yogic philosophy and taking its teachings more metaphorically or poetically, rather than literally. Yoga can be practiced at all ages and stages of life and co-exist with most any religion or worldview. It can provide guidance and support from cradle to grave, from calming babies to facing death. And, in between, there are yoga vacations to take, vegetarian cuisine to eat, Ayurvedic medicine for healing, nutrition to maintain health, ethical principles to follow; and, of course, there are library resources about all of these to collect.
Librarians and those new to yoga must be mindful that yoga should only be taught by knowledgeable teachers, lest there be confusion about the asanas or even injuries. So, anyone interested in yoga should find a local class with a well-trained instructor who can answer questions, demonstrate postures and correct alignment, provide feedback and adjustments, and recommend favorite books. Librarians, too, should seek out local yoga teachers who can make recommendations and direct their students to the library. Controversies and misunderstandings include everything from cultural appropriation to the dangers of overstretching to scandals involving teachers. Although most yoga instructors receive at least two hundred hours of training, not all do, and, even with good teachers, verbal instructions can be confusing, and big classes limit personal attention. Thus, books and online resources are a welcome supplement to those interested in developing a home practice.

Here, you will find well-regarded titles, but undoubtedly, some excellent works are excluded and some may be out of print (although copies can be obtained through interlibrary loan and book resellers). There are thousands of wellreviewed books and book length bibliographies about yoga resources. You can easily find entire articles about Ayurveda, vegetarian cooking, yoga videos, or fiction about yoga. The challenge for librarians interested in meeting this information need lies precisely in facing the quantity and quality of available resources, as well as in understanding yoga's more esoteric ideas. Because of its enduring popularity and variety, there is seemingly no end to what librarians could collect. Nonetheless, whether people are interested in yoga for physical or spiritual reasons or for self-awareness or universal awareness, both public and academic librarians have plenty of motivation and opportunity to develop collections in this area. (Namaste.)

\section{REFERENCE SOURCES}

Titles contained in this section include useful reference works, such as bibliographies, encyclopedias, and pronunciation dictionaries.

Bachman, Nicolai. The Language of Yoga: Complete A to Y Guide to Asana Names, Sanskrit Terms, and Chants. Boulder, CO: Sounds True, 2005 (ISBN: 978-1-5917-9281-9).

This reference book provides definitions and pronunciations for more than three hundred Sanskrit terms, and includes English definitions and illustrations for more than two hundred yoga postures. Includes audio CDs of pronunciations and chants.

Callahan, Daren. Yoga: An Annotated Bibliography of Works in English, 1981-2005. Jefferson, NC: McFarland, 2007 (ISBN: 978-0-7864-3162-5).

Librarian Callahan's exhaustive bibliography of more than 2,400 scholarly and popular books, periodicals, 


\section{THE ALERT COLLECTOR}

dissertations, theses, manuals, and conference proceedings is organized alphabetically with author, title, and subject indexes.

Jarrell, Howard R. International Yoga Bibliography: 1950 to 1980. Metuchen, NJ: Scarecrow, 1981 (ISBN: 978-0-81081472-1).

Jarrell's title covers more than 1,700 resources published in multiple languages, including doctoral dissertations and theses, books, journals, magazine articles, and yoga periodicals; with author, title, and subject indexes.

Larson, Gerald James, and Ram Shankar Bhattacharya, eds. Encyclopedia of Indian Philosophies. Vol. 12, Yoga: India's Philosophy of Meditation. Delhi: Motilal Banarsidass, 2011 (ISBN: 978-8-1208-3349-4).

Tracing the history of yoga from the Yoga Sutras to modern yoga, with an emphasis on Patajala yoga, hatha yoga, and related systems, this comprehensive 786-page volume includes summaries of seventy-five classic Sanskrit texts.

\section{CLASSIC SANSKRIT TEXTS}

Titles in this section include the classical texts from which modern yoga has evolved. Standard academic editions are included, as well as versions recommended by yogis for their interpretive insight. (Older, public domain versions are also available online, although print may be welcome.)

Doniger, Wendy. The Rig Veda: An Anthology: One Hundred and Eight Hymns. New York: Penguin Classics, 2000 (ISBN: 978-0-1404-4402-5).

Yoga was first mentioned in the Rig Veda, the 1500 BCE collection of Vedic hymns that later became one of the sacred texts of Hinduism. It speaks of "yoking," which is how yoga is generally translated, as a discipline to control and harness the breath.

Eknath, Easwaran. The Bhagavad Gita. Petaluma, CA: Nilgiri, 1985 (ISBN: 978-0-9151-3236-2).

Miller, Barbara S., and Barry Moser. The Bhagavad-Gita: Krishna's Counsel in Time of War. New York: Columbia University Press, 1986 (ISBN: 978-0-2310-6468-2).

Mitchell, Stephen. Bhagavad Gita: A New Translation. New York: Harmony, 2000 (ISBN: 978-0-6096-0550-9).

Prabhavananda, Swami, Christopher Isherwood, and Aldous Huxley. Bhagavad-Gita: The Song of God. Signet, 2002 (ISBN: 978-0-8748-1008-0.)

This poetic discourse describes the yogas of devotion, service, meditation, and study, as well as yoga techniques. Written by an anonymous sage sometime in the third or fourth century BCE, and included as the sixth book (about 700 stanzas) in the great Indian epic, the Mahabharata.

Olivelle, Patrick. Upanișads. Oxford: Oxford University Press, 1996 (ISBN: 978-0-1995-4025-9).

The Upanișads (600 BCE-200 CE) are Vedic scriptures, expounding the foundational concepts of Hinduism, Buddhism, and Jainism, as well as yoga practices. This edition, edited by a noted scholar who incorporates recent historical and philological understandings in a valuable introduction, is useful for non-specialists, as well as academics.

Bouanchaud, Bernard, and Rosemary Desneux. The Essence of Yoga: Reflections on the Yoga Sutras of Patanjali. Portland, OR: Rudra, 1997 (ISBN: 978-0-9158-0169-5).

Iyengar, B. K.S, Yehudi Menuhin, and Patanjali. Light on the Yoga Sutras of Patanjali: Patanjala Yoga Pradipika. London: Aquarian/Thorsons, 2002 (ISBN: 978-0-0071-4516-4).

Patanjali, and Georg Feuerstein. The Yoga-Sutra of Patanjali: A New Translation and Commentary. Folkestone, UK: Dawson, 1979 (ISBN: 978-0-8928-1262-2).

Patanjali, and Barbara S. Miller. Yoga: Discipline of Freedom: the Yoga Sutra Attributed to Patanjali; a Translation of the Text, with Commentary, Introduction, and Glossary of Keywords. Berkeley, CA: University of California Press, 1996 (ISBN: 978-0-5202-0190-3).

Satchidananda, and Patanjali. The Yoga Sutras of Patanjali. Yogaville, VA: Integral Yoga, 2002 (ISBN: 978-0-9320-4028-2).

Attributed to the sage Patanjali, the 195 aphorisms of the Yoga Sutras (second century CE), a synthesis of earlier teachings and traditions, advises readers how to achieve mastery over their desires and emotions and, in so doing, achieve spiritual growth

Muktibodhananda, Saraswati, Satyananda, and Svatmarama. Hatha Yoga Pradipika: Light on Hatha Yoga: Including the Original Sanskrit Text of the Hatha Yoga Pradipika with Translation in English. Munger, Bihar, India: Yoga Publications Trust, 1998 (ISBN: 978-8-1857-8738-1).

Svatmarama, Elsy Becherer, and Hans-Ulrich Rieker. Hatha Yoga Pradipika. New York: HarperCollins, 1990 (ISBN: $978-$ 0-0444-0600-6).

This fifteenth century CE manual is the classic text of Hatha Yoga as it was conceived and practiced by early Hatha Yoga masters and includes asana, pranayama, chakras, bandhas energy locks), and nadis (energy channels). 


\section{HISTORY AND BIOGRAPHY}

The development of yoga spans thousands of years. Its history and the lives of its fascinating teachers both exemplify and demystify the philosophy and practice of yoga.

Alter, Joseph S. Yoga in Modern India: The Body between Science and Philosophy. Princeton, NJ: Princeton University Press, 2004 (ISBN: 978-0-6911-1874-1).

This scholarly work examines the history of yoga in India, and its dramatic development during the twentieth century.

Eliade, Mircea, Willard R. Trask, and David G. White. Yoga: Immortality and Freedom. Princeton, NJ: Princeton University Press, 2009 (ISBN: 978-0-6911-4203-6).

First published in English in 1958, this was one of the earliest comprehensive scholarly surveys of yoga, forming the basis for western understandings of yoga practice and philosophy.

Feuerstein, Georg. The Yoga Tradition: Its History, Literature, Philosophy, and Practice. Prescott, AZ: Hohm, 2001 (ISBN: 978-1-8907-7218-5).

The late Feuerstein, a German Indologist and translator, offers non-specialists a comprehensive study of the origins of yoga history, philosophy, and practice in the context of Indian religions.

Goldberg, Michelle. The Goddess Pose: The Audacious Life of Indra Devi, the Woman Who Helped Bring Yoga to the West. New York: Vintage, 2016 (ISBN: 978-0-3074-7744-6).

Journalist Goldberg offers a fascinating and accessible biography of Indra Devi (1899-2002), the globetrotting woman who exposed the western world to the practice and philosophy of yoga.

Goldberg, Philip. American Veda: From Emerson and the Beatles to Yoga and Meditation: How Indian Spirituality Changed the West. New York: Harmony, 2010 (ISBN: 978-0-3855-2134-5).

Intended for all readers, Philip Goldberg's American Veda tells the story of how the ancient philosophies and practices of yoga have profoundly affected the worldview of millions of Americans while simultaneously being transformed by western mores.

Yogananda, Paramahansa. Autobiography of a Yogi. Los Angeles: Self-Realization Fellowship, 1998 (ISBN: 978-0-87612079-8).

First published in 1946, this classic memoir by a preeminent guru (teacher) still resonates with many practitioners today searching for a path to self-discovery and self-actualization.

\section{DEVELOPING A YOGA PRACTICE}

These works cover the physical practice of yoga as well as how to understand and apply its philosophy. Most are suitable for beginners.

Cope, Stephen. The Wisdom of Yoga: A Seeker's Guide to Extraordinary Living. New York: Bantam, 2006 (ISBN: 978-05533-8054-5).

The author, a western-trained psychotherapist, goes beyond presentation of yoga positions to offer a funny and profound guide to the ancient wisdom of the Yoga Sutra and its relevance to the modern practice of yoga.

Cope, Stephen. Yoga and the Quest for True Self. New York: Bantam, 2000 (ISBN: 978-0-5533-7835-1).

Drawing on the author's personal journey, this book demystifies the philosophy, psychology, and practice of yoga, revealing its practical applications to many challenges of contemporary life,

Desikachar, T. K. V. The Heart of Yoga: Developing a Personal Practice. Rochester, VT: Inner Traditions International, 1999 (ISBN: 978-0-8928-1764-1).

Drawing upon the teachings of Krishnamacharya, one of the greatest modern yogis, his son, Desikachar, describes all elements of yoga practice-poses, breathing, meditation, and philosophy for yoga students. Highly recommended for beginner practitioners seeking a broader context for their exploration of yoga.

Farhi, Donna. The Breathing Book: Good Health and Vitality Through Essential Breath Work. New York: Henry Holt, 1996. (ISBN: 978-0-8050-4297-9).

This clearly written and accessible guide shows how proper breathing techniques can reduce stress and dramatically improve both physical and mental health; includes strategies for enhancing general energy and well-being, as well as addressing numerous more specific health issues.

Farhi, Donna. Bringing Yoga to Life: The Every Day Practice of Enlightened Living. San Francisco: HarperCollins, 2005 (ISBN: 978-0-0607-5046-6).

For readers seeking to integrate the spiritual and philosophical teachings of Patanjali's Yoga Sutras into their daily lives, this engaging book by a renowned teacher emphasizes the challenges and rewards of non-physical aspects of yoga practice.

Folan, Lilias M. Lilias! Yoga: Your Guide to Enhancing Body, Mind, and Spirit in Midlife and Beyond. New York: Skyhorse, 2011 (ISBN: 978-1-6160-8451-6).

This popular instructor began teaching on television in the 1970s and offers safe and creative yoga routines for mature practitioners. 


\section{THE ALERT COLLECTOR}

Frawley, David. Yoga: The Greater Tradition. San Rafael, CA: Mandala, 2008. (ISBN: 978-1-6010-9016-4).

For readers new to the spiritual aspects of yoga, this title offers brief introduction to yoga tradition and practice by a noted Vedic scholar.

Iyengar, B. K. S. Light on Yoga: Yoga Dipika. New York: Schocken, 1979. (ISBN: 978-0-8052-1031-6).

The definitive modern guide to yoga, with illustrations of positions and descriptions of breathing exercises, as well as an account of the philosophy of yoga. Offers guidance for beginners to advanced students.

Iyengar, B. K. S., John J. Evans and Douglas Abrams. Light on Life: The Journey to Wholeness, Inner Peace and Ultimate Freedom. Emmaus, PA: Rodale, 2006. (ISBN: 978-1-5948-6524-4).

This companion to Light on Yoga focuses on the intellectual and spiritual aspects of yoga; offers more advanced practitioners the wisdom of a master teacher.

Iyengar, B .K. S. The Tree of Yoga: The Definitive Guide to Yoga in Everyday Life. New York: HarperCollins. 2013. (ISBN: 9780-0079-2127-0).

Drawn from Iyengar's teachings and lectures, this work covers the therapeutic nature of yoga for enhancing everyday life and health.

Jamieson, Theresa. Conscious Birthing: Yoga and Meditation for Pregnancy. Sally Milner, 2009. (ISBN: 978-1-8635-1391-3).

These exercises and postures are specifically and carefully designed for each stage of pregnancy, and illustrate physical postures, along with conscious breathing and meditation exercises to help focus the mind.

Kempton, Sally. Meditation for the Love of It: Enjoying Your Own Deepest Experience. Boulder, CO: Sounds True, 2011. (ISBN: 978-1-6040-7081-1).

Kempton, an expert teacher, offers valuable techniques for anyone interested in practicing and enjoying the benefits of meditation.

Kraftsow, Gary. Yoga for Transformation: Ancient Teachings and Holistic Practices for Healing Body, Mind, and Heart. New York: Penguin Compass, 2002. (ISBN: 978-0-1401-9629-0).

Useful for more experienced yoga students, Kraftsow's Yoga for Transformation introduces yoga techniques that treat the emotions, mind, heart, and soul, as well as the physical body.

Lasater, Judith. Living Your Yoga: Finding the Spiritual in Everyday Life. Berkeley, CA: Rodmell, 2015. (ISBN: 978-19304-8536-5).

An expanded edition of a popular and accessible work meant for all readers, Lasater's Living Your Yoga connects traditional yoga philosophy from the Yoga Sutra and the Bhagavad Gita to the experiences of everyday life.
Lasater, Judith. Relax and Renew: Restful Yoga for Stressful Times. Berkeley, CA: Rodmell, 2005 (ISBN: 978-1-93048529-7).

Geared toward all readers, this Lasater title offers methods of restorative yoga, including relaxation poses and breathing practices to relieve chronic stress.

Payne, Larry, Georg Feuerstein, Sherri Baptiste, Stephan Bodian, Therese Iknoian, LaReine Chabut, and Doug Swenson. Yoga All-in-One for Dummies. Somerset, NJ: Wiley, 2015 (ISBN: 978-1-1190-2272-5).

This Dummies title incorporates six works by well-regarded yoga teachers published in one volume. It offers beginning yogis valuable details about the practice, including links to online demonstrations..

Radha, Swami Sivananda. Kundalini Yoga for the West. Spokane, WA: Timeless, 2004 (ISBN: 978-1-9320-1804-2).

This classic work, written by the first Western woman to become a Swami, makes the philosophy of Kundalini, with its emphasis on chakras (energy centers of the body), more accessible to those seeking to incorporate its lessons into modern life.

Schiffmann, Erich. Yoga: The Spirit and Practice of Moving into Stillness. New York: Pocket, 1996 (ISBN: 978-0-67153480-6).

American yoga master Schiffmann combines hatha yoga and meditation practice into an easy to follow program for all levels of yoga practitioners.

Wallis, Christopher D. Tantra Illuminated: The Philosophy, History, and Practice of a Timeless Tradition. Mattamayura, 2013 (ISBN: 978-0-9897-6130-7).

This well-written introduction to the central teachings and transformative practices of Tantra, a 1,500-year-old tradition, uses translations from primary Sanskrit sources.

White, David G., ed. Yoga in Practice. Princeton, NJ: Princeton University Press, 2011 (ISBN: 978-0-6911-4086-5).

This anthology of primary texts from diverse yoga traditions includes Hindu, Buddhist, Jain, and Islamic sources; with introductions to each selection by the editor; for students and practitioners.

\section{HEALTH/SCIENCE}

Broad, William J. The Science of Yoga: The Risks and the Rewards. New York: Simon \& Schuster, 2012 (ISBN: 978-14516-4142-4).

Written by a New York Times science writer, this volume debunks myths, explains the benefits of yoga for modern life, and offers a vision for how ancient yoga practice can be updated and improved for modern practitioners. 
Calais-Germain, Blandine. Anatomy of Movement. Rev. ed. Seattle, WA: Eastland, 2007 (ISBN: 978-0-9396-1657-2).

Written by a dance teacher and performer, Anatomy of Movement offers thousands of drawings to illustrate anatomical structures and systems and their functional connections to yoga and other physical activities.

Kaminoff, Leslie, and Amy Matthews. Yoga Anatomy. 2nd ed. Champaign, IL: Human Kinetics, 2011 (ISBN: 978-14504-0024-4).

This bestselling anatomy guide for yoga includes full-color anatomical illustrations of asanas and vinyasas (sequences of poses), and brings into focus underlying structures and principles of various yoga movements.

Coulter, H D. Anatomy of Hatha Yoga: A Manual for Students, Teachers, and Practitioners. Honesdale, PA: Body and Breath, 2010 (ISBN: 978-0-9707-0061-2).

Coulter, PhD in anatomy from the University of Tennessee for Health Sciences, offers this comprehensive and authoritative work, with full color illustrations, connecting the traditions of hatha yoga with modern understandings of anatomy and physiology.

\section{TEACHING YOGA}

These texts are good introductions for advanced practitioners considering sharing their practice with others.

Farhi, Donna. Teaching Yoga: Exploring the Teacher-Student Relationship. Berkeley, CA: Rodmell, 2006 (ISBN: 978-19304-8517-4).

Fahri's Teaching Yoga explores ethical standards for yoga teachers, with an emphasis on developing and maintaining healthy professional relationships with students.

Ippoliti, Amy, and Taro Smith. The Art and Business of Teaching Yoga: The Yoga Professional's Guide to a Fulfilling Career. Novato, CA: New World Library, 2016 (ISBN: 978-1-60868227-0).

The authors include information about how to establish a career as a yoga teacher, and the challenges of running one's own yoga studio. Marketing, social media, networking, and managing business finances is also included.

Stephens, Mark. Teaching Yoga: Essential Foundations and Techniques. Berkeley, CA: North Atlantic, 2010 (ISBN: 9781-5564-3885-1).

This title, for new and experienced teachers, covers basic topics in teacher training classes, including yoga philosophy and history, eleven styles of contemporary yoga practice, and aspects of anatomy and physiology. Stephens addresses 100 percent of the teacher-training curriculum standards set by the Yoga Alliance, an accrediting body.

Stephens, Mark. Yoga Sequencing: Designing Transformative Yoga Classes. Berkeley, CA: North Atlantic, 2012 (ISBN: $978-$ 1-5839-4497-4).

Stephens has trained more than 1,000 yoga teachers twenty-plus years. This title offers sequences of yoga postures for beginning, intermediate and advanced levels and types of yoga classes, including yoga for kids, expectant mothers, women undergoing menopause, and seniors.

\section{WEB RESOURCES}

There are many article, blogs, websites, and videos to explore online, including these highly recommended sites.

Do Yoga With Me (https://www.doyogawithme.com)

Do Yoga With Me features hundreds of free, streaming yoga lessons taught by highly qualified instructors. Some content is for beginners but overall the site is better suited to intermediate practitioners who have taken a few basic yoga classes.

Yoga Alliance (http://yogaalliance.org)

The Yoga Alliance is a large nonprofit association of over 84,000 yoga teachers and schools. The site includes a powerful registry and search tool for locating and finding reviews of registered yoga teachers, classes, and schools across the United States and beyond.

Yoga Journal (http://yogajournal.com)

Founded in 1975, Yoga Journal's popular and inclusive monthly print magazine and website covers all aspects of yoga practice. Sections of the website offer tips on integrating yoga into your personal life, how to become a teacher, and "Yoga 101" which has information on yoga philosophy, Sanskrit terms, and video tutorials.

Yoga International (http://yogainternational.com)

The Himalayan Institute's Yoga International site includes articles, video tutorials, workshops, and courses about all aspects of yoga. Some content requires a membership for access. The group offers an app for Android and IOS devices that has guided meditations, tutorials and more. 